\title{
Downregulation of Stemness Genes and Induction of Necrosis in Rat LA7 Cancer Stem Cells Induced Tumors Treated with Starved Fibroblasts Culture Supernatant
}

\author{
Roghayeh Pourbagher ${ }^{1,2}$, Hossein Ghorbani ${ }^{3}$, Haleh Akhavan-Niaki², \\ Seyed Gholam Ali Jorsaraei ${ }^{4}$, Sadegh Fattahi ${ }^{2}$, Sahar Ghooran ${ }^{3}$, \\ Zeinab Abedian ${ }^{1,5}$, Masoumeh Ghasemi ${ }^{2}$, Fatemeh Saeedi ${ }^{1,2}$, Negar Jafari ${ }^{1,2}$, \\ Behnam Kalali ${ }^{6}$, Amrollah Mostafazadeh*2
}

\begin{abstract}
Background: Stem cell differentiation therapy is a promising strategy in cancer treatment. we show that protein cocktail prepared from serum starved fibroblasts has therapeutic potential based on this strategy.

Methods: The condition medium was prepared from foreskin isolated fibroblasts and analyzed by Liquid chromatography electrospray ionization mass spectrometry-mass spectrometry (LC-ESI-MS/MS). LA7 mammary gland cancer stem cells originated tumors were induced in Sprague Dawley rats. The rats treated subcutaneously with DMEM (group A), condition medium (group B), or normal saline (group C) once daily for 7 days. Then the tumors were removed and divided into the two parts, one part was used to quantify gene expression by stem-loop RT-qPCR assay and the other part was used for Hematoxylin \& Eosin (H \& E), Giemsa, and immunohistochemistry (IHC) staining.

Results: All induced tumors appeared as sarcomatoid carcinoma (SC). Immunohistochemistry staining confirmed this conclusion by recognizing the tumor as $\mathrm{Ki}^{+} 7^{+}$, cytokeratin ${ }^{+}$, vimentine ${ }^{+}$, and estrogen receptor negative SC. RT-qPCR analysis revealed that Oct4-, Sox-2, Nanog-gene expression was much reduced in the condition medium treated tumors versus proper controls $(\mathrm{p}<0.05)$. Tissue necrosis was more prevalent in this group while tumors volume was diminished almost by $40 \%$. The LC-ESI-MS/MS analysis unrevealed the stemness reducing and the cell death inducing proteins such as, pigment epithelium-derived factor (PEDF), insulin like growth factor binding protein-5 (IGFBP-5) and -7 (IGFBP-7) in the condition medium.

Conclusions: This study showed that the substances released from starved human fibroblasts were able to down-regulate the stemness-related genes and induce necrosis in LA7 derived tumors.
\end{abstract}

Keywords: Breast cancer, Cancer Stem cells, Cell differentiation, Fibroblasts, Gene expression.

\section{Introduction}

Epithelial cell derived carcinoma type of cancers such as breast cancer (BC), comprises

almost $80-90 \%$ of cancer-mediated diseases in human (1). By basement lamina, epithelial cells

1: Student Research Committee, Babol University of Medical Sciences, Babol, Iran.

2: Cellular and Molecular Biology Research Center, Health Research Institute, Babol University of Medical Sciences, Babol, Iran.

3: Department of Pathology, Rohani Hospital, Babol University of Medical Sciences, Babol, Iran.

4: Fatemeh Zahra Infertility and Reproductive Health Research Centre, Health Research Institute, Babol University of Medical Sciences,

Babol, Iran.

5: Dental Materials Research Center, Dental Faculty, Babol University of Medical Sciences, Babol, Iran

6: Institute for Medical Microbiology, Immunology and Hygiene, Technische Univensität München, Munich, Germany.

*Corresponding author: Amrollah Mostafazadeh; Tel: +98 9112113998; E-mail: a.mostafazadeh@mubabol.ac.ir.

Received: 28 Sep, 2020; Accepted: 11 Oct, 2020 
are separated from the underlying supportive connective tissue in which fibroblasts are found in a remarkable quantity compared to epithelial cells. For instance, in the terminal ductal lobular unit of normal breast, and tumor derived in situ lesion, the fibroblasts to epithelial cells ratio varies from $1: 2$ to $1: 3$ (2). These cells play some pivotal roles in the regulation of epithelial cell development and function in health and disease conditions such as cancers. For instance, normal associated fibroblasts (NAFs) are able to inhibit the normal epithelial cell proliferation when the number of fibroblasts is low because these cells promote epithelial cell proliferation at high cell density (2). However, a limited number of researchers have paid attention to functional relationship between normal fibroblasts and epithelial cells. On the other hand, cancer-associated fibroblasts (CAFs) promote cancer cell survival and progression (2). Particularly, a subset of CAFs with CD10+GRP77+ phenotype can promote tumor formation and chemo-resistance through providing a survival niche for CSCs in patients with breast and lung cancers (3). Tissue specific stem cells are milestone cells in tissue hemostasis. These undifferentiated cells were characterized by self-renewing, rendering them a prolonged lifespan, which in turn exposes these parent cells to a variety of mutagenic factors required for normal stem cell transformation to a special type of tumorigenic stem cells called CSCs such as breast cancer stem cells (BCSCs). Accumulating data show that these cells are resistant to radiotherapy and chemotherapy, causing the relapse of cancer related diseases after treatment despite such current available cancer therapies.

Different factors play roles in differentiation of breast normal stem cell into BCSC. On the one hand, Notch, Hedgehog, and Wnt signaling pathways may be dysregulated in breast normal stem cells leading to differentiation into CSCs (4). On the other hand, some transcriptional factors including octamer-binding transcription factor 4 (Oct4), sex determining region Y-box 2 (Sox2), the homeobox domain transcription factor Nanog and C-myc also play some pivotal roles in this differentiation $(5,6)$. Oct4 and Sox 2 have a key role in maintaining and inducing pluripotency (7), and give to tumor growth and metastasis (8-10). While Nanog is considered as a key regulator of embryonic development and cellular reprogramming and takes part in selfrenewal of CSCs (11). C-myc is an oncoprotein with various functions in apoptosis, cell growth and division, and differentiation (6). Many earlier studies showed that the expression of Yamanaka factors and Nanog are associated with CSCs such that reduction in expression of these genes leads to differentiation of the CSCs into mature cancer cells (12-14). Currently, the strategy of cancer therapy through CSC differentiation has attracted the interest of many researchers worldwide. Interestingly, BCSCs in tumor microenvironments show a high level of plasticity enabling them to change their state between mesenchymal-like cells and epitheliallike cells (15). This plasticity is important in tumor establishment and metastasis $(15,16)$.

Thus, the application of some methods to mitigate the expression of cancer stemness related genes may have the potential to improve the current approaches in the field of cancer therapy. In line with this strategy, we studied the behavior of fibroblasts under a special type of situation which mimics the dominant conditions in microenvironments of solid tumor, i.e., cultivation under stress of serum starvation stress. This condition is considered as a model for the in vitro study of different aspects of tumor biology $(17,18)$. In the tumor microenvironment, cancerous cells change their metabolic program to aerobic glycolysis (Warburg effect) (19). We observed that fibroblasts derived from infant skin can mimic such behaviors under serum starvation stress (20). In addition, these starved fibroblasts secret some proteins with growth factor like activity. These proteins were able to guarantee fibroblasts survival in harsh conditions like serum starvation, and similar to growth factor, were able to induce sustained calcium influx in fibroblasts, and accelerate the proliferation of these cells after re-feeding with serum (20). Recently, we showed that the condition medium, prepared from 16h-starved fibroblasts (16h-SFS solution), was able to reduce the 
expression of stemness- related genes, to inhibit cell migration and to induce and necrotic type of cell death in LA7 rat cancer stem cells in vitro (21). LA7 is a well-known rat mammary gland cancer stem cells that can be differentiated to all cell lineages of the mammary gland and is able to induce heterogeneous tumors in non-obese diabetic- SCID mice (22). Tumor induction by transplantation of LA7 cells in animal model, is recently considered as a favored method in cancer research (23). Here, we showed that 16h-SFS solution comprised of some proteins with well-known ability in reduction of the expression of stemness-related genes and in induction of cell death, upon analyzing this solution by LC-ESI-MS/MS. Some more important types of such proteins are pigment epithelium-derived factor (PEDF), insulin like growth factor binding protein-5 (IGFBP-5), and insulin like growth factor binding protein-7 (IGFBP-7). Under stress conditions, PEDF protects the cells via promoting mitochondrial stability and by regulating reactive oxygen species (ROS) generation and degradation (24). IGFBP5 is reported to modulate apoptosis of breast cancer cells through more than one mechanism (25), and IGFBP7 is also known as a tumor suppressor gene for a variety of cancers (26).

In the present study, we showed that substances derived from serum starved human fibroblasts including PEDF and IGFBP-5 /7, were able to downregulate the stemness related genes such as Nanog, Oct4 and Sox2 in LA7 induced tumors in Sprague Dawley rats, inhibited the tumor growth in vivo, and promoted the development of focal necrosis in these tumors.

\section{Materials and Methods}

\section{Preparation of 16h-SFS solution}

We isolated the fibroblasts from fresh foreskin (newborn; $\mathrm{n}=3$, age; 1 to 1.5 months) based on the method already described (27). The isolated cells were cultured in Dulbecco's Modified Eagle's Medium (DMEM, Biowest, France), supplemented with $10 \%$ fetal bovine serum (FBS), (Sigma, Germany), streptomycin $(100 \mu \mathrm{g} / \mathrm{mL})$ and Penicillin (100 IU/mL), at 37
${ }^{\circ} \mathrm{C}$ with $5 \% \mathrm{CO} 2$ saturation, until the cell number reached adequate levels to carry out the serum starvation procedure according to the method already reported (28). Then at $80 \%$ confluency in $75 \mathrm{~cm}^{2}$ cell culture flask, the cells were washed with phosphate buffered saline (PBS) twice, and cell culture was continued under standard conditions for $16 \mathrm{~h}$ in serum free, glucose containing DMEM supplemented with streptomycin $(100 \mu \mathrm{g} / \mathrm{mL})$ and Penicillin (100 IU/mL) Finally, the cell culture supernatants were harvested, pooled, and stored at $-20{ }^{\circ} \mathrm{C}$ until use. The Ethics Committee of Babol University of Medical Sciences approved this research. Because the foreskin specimens were collected anonymously from children and given the local culture perception that considers the foreskin as a disposable tissue, this committee waived the requirement for obtaining written consent from children's parents in the present research.

\section{Mass spectrometry analysis of 16h-SFS solution}

Protein components in 16h-SFS solution were determined through analyzing this solution using LC-ESI-MS/MS performed by TopLAB Company (Munich, Germany). Briefly, one $\mathrm{mL}$ of 16h-SFS solution (approximately $20 \mu \mathrm{g}$ protein) was frozen for $66 \mathrm{~h}$ at $-80{ }^{\circ} \mathrm{C}$, vacuum dried in a lyophile overnight, and resolved in 50 $\mu \mathrm{L}$ buffer (8 M urea/0.4 M NH4HCO3, $\mathrm{pH} 8.5$ ). The sample was reduced with $5 \mu \mathrm{L}$ of dithiothreitol $(45 \mathrm{mM})$ for $30 \mathrm{~min}$ at $55{ }^{\circ} \mathrm{C}$ and alkylated with $5 \mu \mathrm{L}$ of iodoacetamide $(100 \mathrm{mM})$ at room temperature in the dark. Enzymatic digestion was performed based on the valid version of the SOP H-VED-001 enzymatische spaltung. The sample was acidified to $1 \%$ trifluoroacetic acid and $10 \mu \mathrm{L}$ of the digest was used for the nano-LC-ESI-MS/MS analysis. High Performance Liquid Chromatography (HPLC) separation was performed using the EASY-nLC1000 system. Mass-spectrometric analysis was carried out on a LTQ Qrbitrap XL mass-spectrometer (Thermo Scientific). NanoLC HPLC separation and online-coupled ESIMS/MS measurement were performed. The LC- 
ESI-MS/MS data were used for a database search with the software MASCOT (Matrix Sciences) using human sequences from SwissProt database. Peptide mass tolerance was set to $50 \mathrm{ppm}$, fragment mass tolerance was set to $0.6 \mathrm{Da}$, and a significance threshold of, $\mathrm{p}<$ 0.05 , was used. An ion score cut off $>26$ (individual ion score greater than 26 indicate identity or extensive homology) was applied for the peptide identification.

\section{Culture of rat breast cancer stem cells}

The LA7 rat mammary gland cancer stem cells, gifted kindly by Dr. Davood Sabour, were cultured in DMEM, (Biowest, France), and supplemented with $10 \%$ fetal bovine serum (FBS, Sigma, Germany), streptomycin $(100 \mu \mathrm{g} / \mathrm{mL})$ and Penicillin $(100 \mathrm{IU} / \mathrm{mL})$ under standard conditions as described above.

\section{Tumor growth in vivo}

The LA-7 cells were trypsinized and resuspended at $6 \times 10^{6}$ viable cells $/ 300 \mu \mathrm{l}$ in PBS and transplanted into five rats right flank mammary fat pad in each group, and then the skin in the operation site was stitched. Before cell transplantation, all of these female Sprague Dawley rats (body weights; $187 \pm 3 \mathrm{~g}$ ) were pretreated subcutaneously with $300 \mu \mathrm{L}$ of DMEM (group A), 16h-SFS solution (group B), or normal saline (group C) once daily, for six constitutive days. This treatment was continued for seven days of post tumor cell transplantation. Tumor growth was monitored daily by measuring the tumor length and width using calipers, and tumor volume $\left(\mathrm{mm}^{3}\right)$ was calculated using the formula: length $\times$ width $^{2} \times$ 0.5 . Moreover, the animals' body weight (BW) was recorded intermittently on days 0 to $11^{\text {th }}$ post tumor transplantation for four times, and the average BW was calculated and compared among groups. The experiment was terminated when tumors reached its maximal size (almost 13 days of post- transplantation of tumor cells). Blood samples were taken from lateral tail vein, and plasma was isolated from all animals at termination and kept at $-20{ }^{\circ} \mathrm{C}$ until use. The tumors were removed and divided into two parts. One part was soaked in RNA later solution (YektaTajhiz Azam, Tehran, Iran) for $24 \mathrm{~h}$ at $4{ }^{\circ} \mathrm{C}$, the solution was removed, and the tissues were frozen at $-80{ }^{\circ} \mathrm{C}$ for RNA analysis, whereas the other part was fixed with formaldehyde for histopathological study. All experiments were carried out with the approval of the Institutional Animal Care and Ethics Committee.

\section{Radiographic analysis}

The radiographic analysis of tumors was performed on the $12^{\text {th }}$ day of post-LA7 cells transplantation. To this end, the rats were intraperitoneally anesthetized with ketamine $(60 \mathrm{mg} / \mathrm{kg})$ and Xylazine $(7.5 \mathrm{mg} / \mathrm{kg})$ to capture radiographic images from right lateral view with Shimatzo system (Flexavision, Japan).

\section{Biochemical analysis}

We measured the plasma glucose, calcium, phosphorus, triglyceride, cholesterol, aspartate aminotransferase (AST), alkaline phosphatase (ALP), and albumin using commercially available kits (Pars Azmoon Co., Tehran, Iran) through Auto-analyzer (Response 910, Dia Sys, Holzheim, Germany).

\section{Hematoxylin \& Eosin $(H \& E)$, Giemsa, and Immunohistochemistry (IHC) staining}

The derived tumor tissue samples were isolated, fixed in formalin and embedded in paraffin. The paraffin blocks were sectioned at 5- $\mu \mathrm{m}$ thickness, and stained with $\mathrm{H} \& \mathrm{E}$. Moreover, Giemsa staining was performed based on the routine method in clinical laboratory to see the mast cells in tissue sections. The number ofmitotic cells and micro vessels was assessed in 10 and 3 high power fields (HPF), respectively, and the presence of focal necrosis and mast cells as well as the pattern of inflammatory cells infiltration were evaluated by a pathologist in a blind manner. Required images were captured using light microscopy (Olympus BX51, Tokyo, Japan).

In addition, for a better evaluation of the tumoral tissues, IHC staining was carried out only for one tumor specimen as a representative of tumoral tissue in all groups. The following monoclonal antibodies were used in IHC study. 
Anti-Ki67 (Dako, Denmark, Clone MIB-1), anticytokeratin (Dako, Denmark, Clone AE1/AE3), anti-vimentin (Dako, Denmark, Clone V9) and anti-estrogen receptors (ER) (Dako, Denmark, Clone 1D5). The sections prepared from tumor related tissues were stained with these antibodies separately according to the manufacturer's instructions and routine clinical laboratory protocols.

\section{Real time quantitative polymerase chain reaction ( $R T-q P C R)$}

Total RNA was extracted from the tumor samples by TRIzol-based RNA extraction procedure (Invitrogen, Carlsbad, CA). The quantity and quality of the extracted RNA was determined by Nanodrop spectrophotometer (Thermo Scientific NanoDrop 2000/2000c, USA) and agarose gel electrophoresis, respectively. Then, the expression levels of the four indicated genes, Sox2, Nanog, Oct4, and $C$-myc were determined in each group, using glyceraldehyde 3-phosphate dehydrogenase (Gapdh) gene as a house-keeping gene.

To quantify gene expression, stem-loop RTqPCR assay was performed, as previously described elsewhere (29). Briefly, cDNA was synthesized using mRNA specific stem loopRT primer and RevertAid Reverse Transcriptase (Fermentas, Lithuania). The primers of the four above mentioned genes were designed using AlleleID 6.0 software (Table 1). RT-qPCR assay was carried out with universal Taqman probe using ABI 7300 realtime PCR system (Applied Biosystems, USA). The PCR amplification was programmed as an initial denaturation at $95{ }^{\circ} \mathrm{C}$ for five min, followed by 45 cycles of $95{ }^{\circ} \mathrm{C}$ for $30 \mathrm{~s}$ and 60 ${ }^{\circ} \mathrm{C}$ for $1 \mathrm{~min}$.

Table 1. Types and characteristics of primers used in this study.

\begin{tabular}{|c|c|c|c|}
\hline $\begin{array}{l}\text { Accession } \\
\text { Number }\end{array}$ & $\begin{array}{l}\text { Gene } \\
\text { Name }\end{array}$ & Primers: 5' 3' & $\begin{array}{l}\text { Amplicon size } \\
\text { (bp) }\end{array}$ \\
\hline NM_017008.4 & GAPDH & $\begin{array}{l}\text { Specific forward primer: } \\
\text { CAGTGCCAGCCTCGTCTCATAG } \\
\text { RT-PCR primer } \\
\text { GTCGTATCCAGTGCTGCGACCGTATGGATGTGTCTGCG } \\
\text { GCGTTTTATCATGCACTGGATACGACCGTTCACACCGA }\end{array}$ & 113 \\
\hline $\begin{array}{c}\text { NM_00110078 } \\
1.1\end{array}$ & Nanog & $\begin{array}{l}\text { Specific forward primer: } \\
\text { CAAGTGTCTGCTACTGAGATGCTC } \\
\text { RT-PCR primer } \\
\text { GTCGTATCCAGTGCTGCGACCGTATGGATGTGTCTGCG } \\
\text { GCGTTTTATCATGCACTGGATACGACCAGGGCTATCTTG }\end{array}$ & 149 \\
\hline $\begin{array}{c}\text { NM_00100917 } \\
8.2\end{array}$ & Oct4 & $\begin{array}{l}\text { Specific forward primer: } \\
\text { TCCCGAGGAGTCCCAGGATATG } \\
\text { RT-PCR primer } \\
\text { GTCGTATCCAGTGCTGCGACCGTATGGATGTGTCTGCG } \\
\text { GCGTTTTATCATGCACTGGATACGACGGCAGATGGTTG }\end{array}$ & 225 \\
\hline $\begin{array}{c}\text { NM_00110918 } \\
1.1\end{array}$ & Sox 2 & $\begin{array}{l}\text { Specific forward primer } \\
\text { CCACCAATCCCATCCAAATTAACG } \\
\text { RT-PCR primer } \\
\text { GTCGTATCCAGTGCTGCGACCGTATGGATGTGTCTGCG } \\
\text { GCGTTTTATCATGCACTGGATACGACTCCCTGCGAAG }\end{array}$ & 196 \\
\hline NM_012603.2 & $C-m y c$ & $\begin{array}{l}\text { Specific forward primer } \\
\text { CAGCAGCGACTCTGAAGAAGAAC } \\
\text { RT-PCR primer } \\
\text { GTCGTATCCAGTGCTGCGACCGTATGGATGTGTCTGCG } \\
\text { GCGTTTTATCATGCACTGGATACGAC CCTGACTCGGAC }\end{array}$ & 180 \\
\hline
\end{tabular}

Stem-loop sequence is underlined; target specific portion of mRNA is shown in italic. 


\section{Statistical analysis}

The data were expressed as mean \pm SD. To examine normality of the data, Kolmogorov Smirnov test was used. For multiple comparisons, One-Way ANOVA along with Tukey test was used. In addition, repeated measure ANOVA was used for analyzing data from one group with different variables. The significance level assigned was $p<0.05$. SPSS ver. 24 software (IBM, USA) was used for statistical analysis.

\section{Results}

\section{Reduction of tumor volume in 16h-SFS} treated rats

In human oncology, the early reduction in tumors size is considered as a proper criterion for response evaluation in cancer therapy (30). To evaluate the gross effects of 16h-SFS solution on LA7 cells' in vivo growth, the tumors' volume was measured in rats treated with this solution and compared with this value in animals receiving DMEM or normal saline. After eight days of LA7 cells transplantation, the tumors were observed to be explanted. Interestingly, on the $13^{\text {th }}$ days, the animals treated with16h-SFS solution exhibited an almost $40 \%$ reduction in tumor size when compared with tumor-bearing animals receiving DMEM, as a background medium for 16h-SFS solution. This reduction rate was slightly less (26\%) in comparison to the normal saline control (Fig. 1a). Our radiographic imaging also confirmed such conclusion (Fig. 1b).
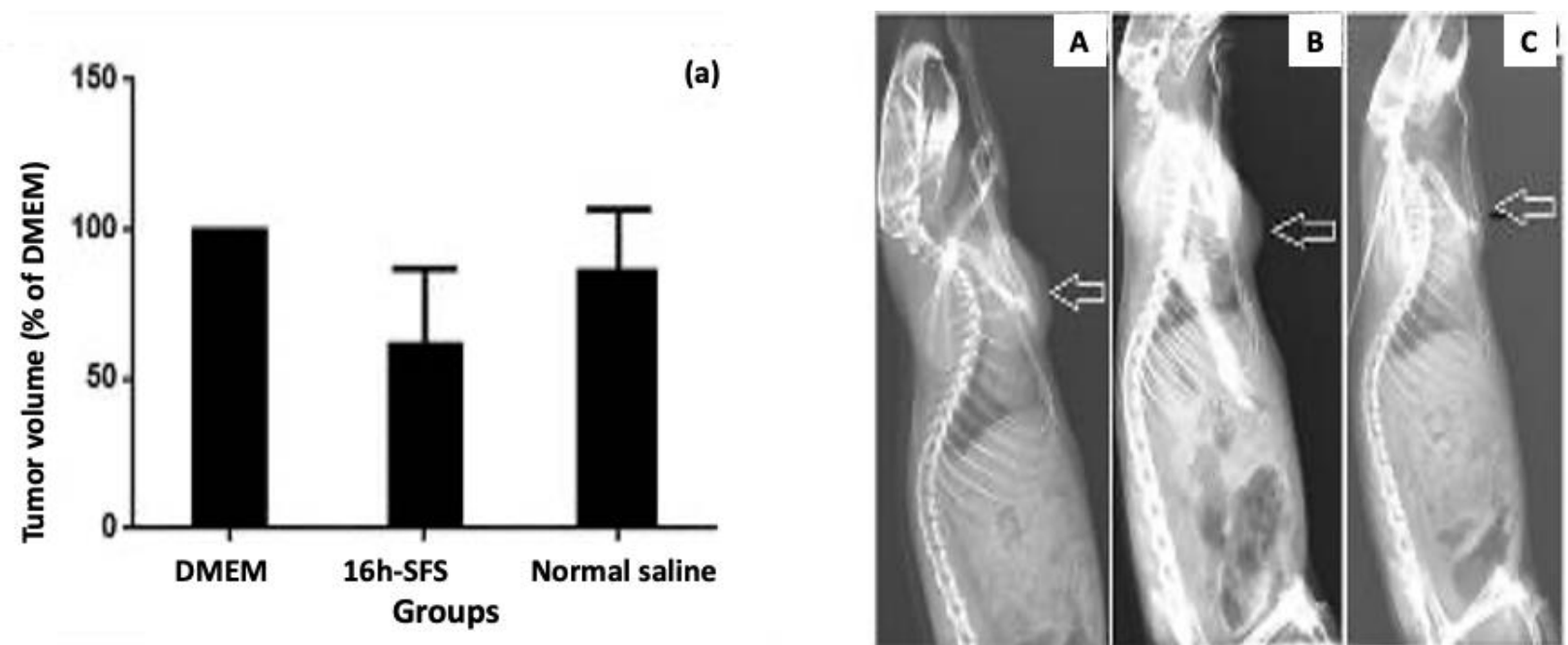

Fig. 1. Tumor's size and X-ray imaging. (a) The volume of tumor after 13 days of LA7 cells transplantation and receiving different solutions. (b) Tumors X-ray imaging. Reduction in the volume of tumors confirmed by X-ray images. A) Normal saline group, B) DMEM group, C) 16h-SFS group. Maximum size was observed in DMEM and minimum size in 16h-SFS treated groups. * shows significant difference compared to the control $(p<0.05)$.

Body weight reduction in16h-SFS treated rats with no significant alternations in blood biochemical parameters

To investigate the overall effects of treatment with 16h-SFS solution on the health of rat in general, we measured the animals' BW daily, along with blood glucose levels, calcium, phosphorus, triglyceride, cholesterol, aspartate aminotransferase (AST), alkaline phosphatase (ALP), and albumin in 16h-SFS treated rats and compared them with those of DMEM and normal saline receiving control. As illustrated in (Table 2), on day 11 post LA7 cell transplantation, a significant reduction in BW was observed in rats treated with $16 \mathrm{~h}-$ SFS solution compared to rats receiving normal saline $(p<0.05)$. However, we did not observe any significant differences among different groups in terms of blood levels of the indicated biochemistry parameters $(p>0.05)$ (Table 2). 
Down regulation of Nanog, Sox 2 and Oct4 gene expression in 16h-SFS solution treated rats

To examine the potential application of $16 \mathrm{~h}$ SFS solution in cancer stem cells differentiation induction, we assessed the expression levels of the four major stemness related genes, i.e., Nanog, Sox2, Oct4 and C$m y c$. To this end, the quality and quantity of extracted RNA were first checked, and then the RT- qPCR analysis was performed. In this experiment, the isolate RNA had appropriate quantity and quality to perform RT- qPCR analysis properly (data not shown). As depicted in Figure 2, there was a significant difference in the expression level of Nanog, Sox2, and Oct4 between 16h-SFS and the two other groups $(\mathrm{p}<0.05)$. However, this difference was not such obvious in the gene expression of $C$-myc.

Table 2. The biochemical parameters and body weight of cancerous rats treated with DMEM, 16h-SFS and Normal saline.

\begin{tabular}{|c|c|c|c|c|}
\hline $\begin{array}{l}\text { Groups } \\
\text { Parameters }\end{array}$ & DMEM & 16h-SFS & Normal saline & p-value* \\
\hline Phosphorus(mg/dL) & $7.24 \pm 0.66$ & $6.96 \pm 1.91$ & $7.44 \pm 0.74$ & 0.1 \\
\hline $\begin{array}{l}\text { Aspartate } \\
\text { aminotransferase } \\
\text { (U/L) }\end{array}$ & $188.8 \pm 34.76$ & $186.6 \pm 15.07$ & $158.6 \pm 24.03$ & 0.07 \\
\hline $\begin{array}{l}\text { Alkaline } \\
\text { phosphates(U/L) }\end{array}$ & $199.2 \pm 30.6$ & $268.4 \pm 41.16$ & $269.2 \pm 62.4$ & 0.23 \\
\hline $\operatorname{Albumin}(\mathrm{g} / \mathrm{dL})$ & $3.34 \pm 0.08$ & $3.44 \pm 0.2$ & $3.28 \pm 0.2$ & 0.87 \\
\hline Glucose (mg/dL) & $78.6 \pm 5.41$ & $82 \pm 7.84$ & $83 \pm 6.32$ & 0.35 \\
\hline Triglyceride(mg/dl) & $72 \pm 13$ & $119.2 \pm 24.32$ & $101 \pm 33.73$ & 0.13 \\
\hline Cholesterol (mg/dL) & $88 \pm 8.15$ & $69.2 \pm 4.49$ & $84.6 \pm 9.68$ & 0.09 \\
\hline Calcium (mg/dL) & $8.82 \pm 0.27$ & $8.28 \pm 0.54$ & $8.8 \pm 0.2$ & 0.24 \\
\hline Body weight (g) & $187.45 \pm 1.61$ & $186.15 \pm 1.03$ & $188.6 \pm 0.61$ & $0.02 * *$ \\
\hline
\end{tabular}
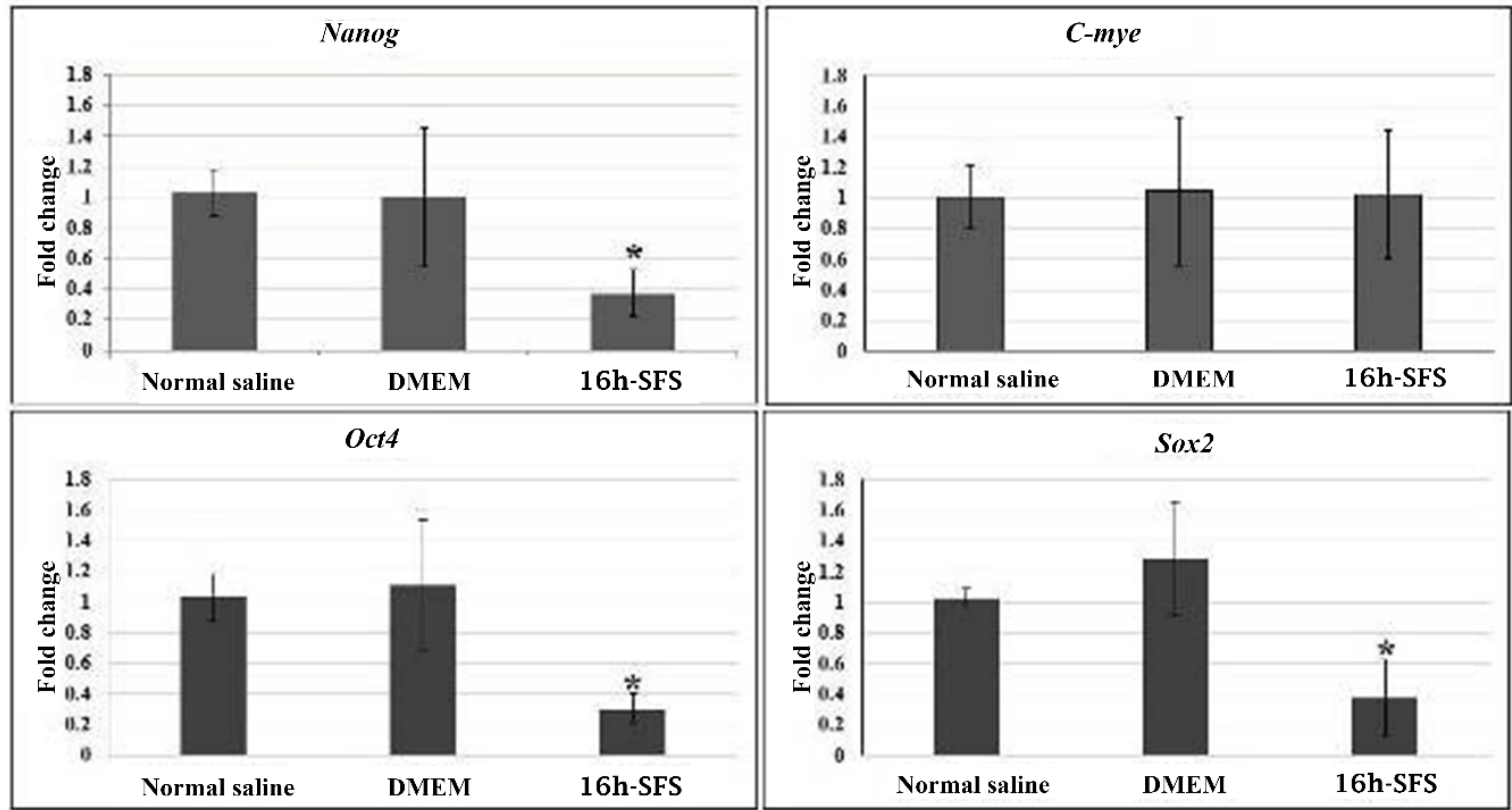

Fig. 2. Alterations in the expression of Nanog, C-myc, Oct-4, and Sox2 in the breast tumors from rat exposed to normal saline, DMEM or 16h-SFS solutions. Data expressed as mean; bars indicate standard deviation. In each panel. * shows significant difference compared to the normal saline and DMEM groups $(\mathrm{p}<0.05)$. 
Higher prevalence of necrosis in 16h-SFS treated LA7 induced tumors

To investigate the microscopic changes in tumors microenvironments in 16h-SFS treated rats the $H \& E$ staining of tumor related tissues was performed and the histopathologic findings were compared with the control group. Overall, the tumors histology showed some different alterations in terms of mitosis, necrosis and inflammatory cells infiltration among groups. Interestingly, four of the five tumors removed from 16h-SFS treated rats showed a focal pattern of necrosis while none of the tumors in normal saline group, and only one of the five isolated tumors from DMEM group showed a pattern (Fig. 3A and Table 3). As illustrated in Figure $3 \mathrm{~B}$ in comparison to normal saline, both 16h-SFS and DMEM solutions were able to reduce the number of mitotic cells in LA7 induced tumors $(\mathrm{p}<0.05)$. The number of micro-vessels in 16h-SFS treated rats was slightly higher than that of DMEM- and normal saline control; however, the difference was not statistically significant (Fig. 3 B and Table 3). To grasp an overall view about the type of tumor infiltrated leucocytes, we focused on such cells in our tumors' histology evaluation. Surprisingly, we were not able to observe mast cells in normal saline treated tumors whereas this type of inflammatory cells was much more prevalent in other groups especially in 16h-SFS treated group (Table 3). Moreover, the poly morphonuclear cells (PMNs) were more prevalent in tumors derived from normal saline treated rats whereas the two other groups exhibited a mixed pattern; both PMNs and MNCs were observed in this group (Table 3).

Table 3. Some histological variables in LA7 induced tumors treated with normal saline, DMEM, and 16h-SFS solutions.

\begin{tabular}{|c|c|c|c|c|}
\hline Groups & $\begin{array}{c}\text { Rat } \\
\text { number }\end{array}$ & $\begin{array}{l}\text { Inflammatory } \\
\text { cell infiltration }\end{array}$ & $\begin{array}{c}\text { Mast } \\
\text { cell }\end{array}$ & $*$ Necrosis \\
\hline \multirow{5}{*}{ DMEM } & 1 & PMNs & + & + \\
\hline & 2 & MNCs & - & - \\
\hline & 3 & PMNs & - & - \\
\hline & 4 & MNCs & - & - \\
\hline & 5 & $\mathrm{MNCs}$ & + & - \\
\hline \multirow{5}{*}{ 16h-SFS } & 1 & PMNs & - & + \\
\hline & 2 & PMNs & + & - \\
\hline & 3 & PMNs & + & + \\
\hline & 4 & MNCs & - & + \\
\hline & 5 & $\mathrm{MNCs}$ & + & + \\
\hline \multirow{5}{*}{ Normal saline } & 1 & PMNs & - & - \\
\hline & 2 & PMNs & - & - \\
\hline & 3 & PMNs & - & - \\
\hline & 4 & MNCs & - & - \\
\hline & 5 & PMNs & - & - \\
\hline
\end{tabular}

*Focal pattern of necrosis was observed. (+) and (-) symbols indicate, "present" and "absent" respectively. PMNs: Polymorphonuclear cells. MNCs: mononuclear cells. 


\section{Serum Starvation and Stem Cell Differentiation}

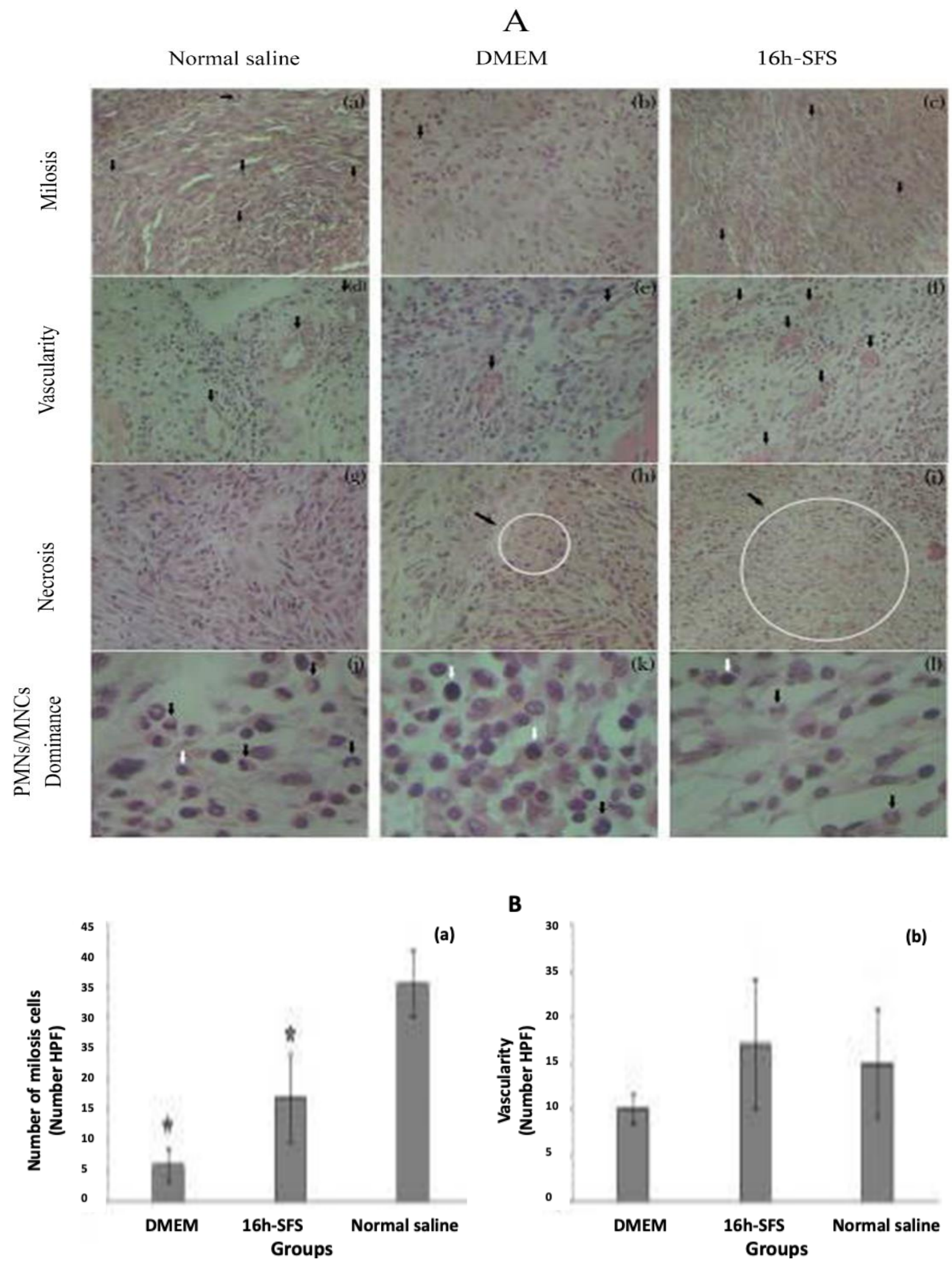

Fig. 3. Histopathologic findings A) The effect of normal saline, DMEM, 16h-SFS solutions on mitosis, vascularity, necrosis and PMNs/MNCs dominance of LA7 induced tumors in rats (H\&E staining). a-c): mitosis (arrow), d-f) vascularity (arrow), g-i) necrosis (arrow) and j-1) PMNs/MNCs dominance (PMNs black arrow, MNCs white arrow). The magnification of a-i is $\times 400$ and j-1 is $\times 1000$. B) Effect of different solutions on angiogenesis and mitosis in LA7 induced tumors (a): The levels of angiogenesis in study groups (b): Changes in the number of cells with mitosis in the three groups. * shows significant difference compared to the normal saline control $(\mathrm{p}<0.05)$. HPF: High-power field. 


\section{LA7-CSCs can be differentiated to poorly} differentiated sarcomatoid carcinoma in rats

Based on the morphological evaluation obtained by H\&E staining, the induced tumors in all rats appeared as sarcomatoid carcinoma. To provide more detailed phenotyping findings, we performed IHC staining. In our IHC study, we investigated the expression of Ki67 antigen, as an indicator of mitosis, cytokeratin, the intermediate filament in epithelial cells, and its counterpart in mesenchymal cells. i.e., vimentin. We also considered the LA7 cells as estrogen receptor positive cells based on a previous report (23); therefore, we used this antigen in our IHC panel. As it can be realized from Figure 4, the LA7 cells transformed to $\mathrm{Ki} 67^{+}$, cytokeratin ${ }^{+}$, vimentin ${ }^{+}$, and estrogen receptor negative cells. Thus, we considered this tumor as poorly differentiated sarcomatoid carcinoma.

\section{Identification of proteins}

To determine the mode of action of the 16hSFS solution at molecular levels, the protein components of this solution should be characterized initially. Three hundred and twenty-four proteins were identified in 16h-SFS solution using LC-ESI-MS/MS technique (data not shown). From these proteins, we derived a short list of proteins with prominent roles in stem cells and cancer biology based on protein scores obtained by mass spectrometry analysis and our literature review. Three of the most important of these proteins are shown in (Table 4). These proteins are PEDF; IGFBP-5; and IGFBP -7.
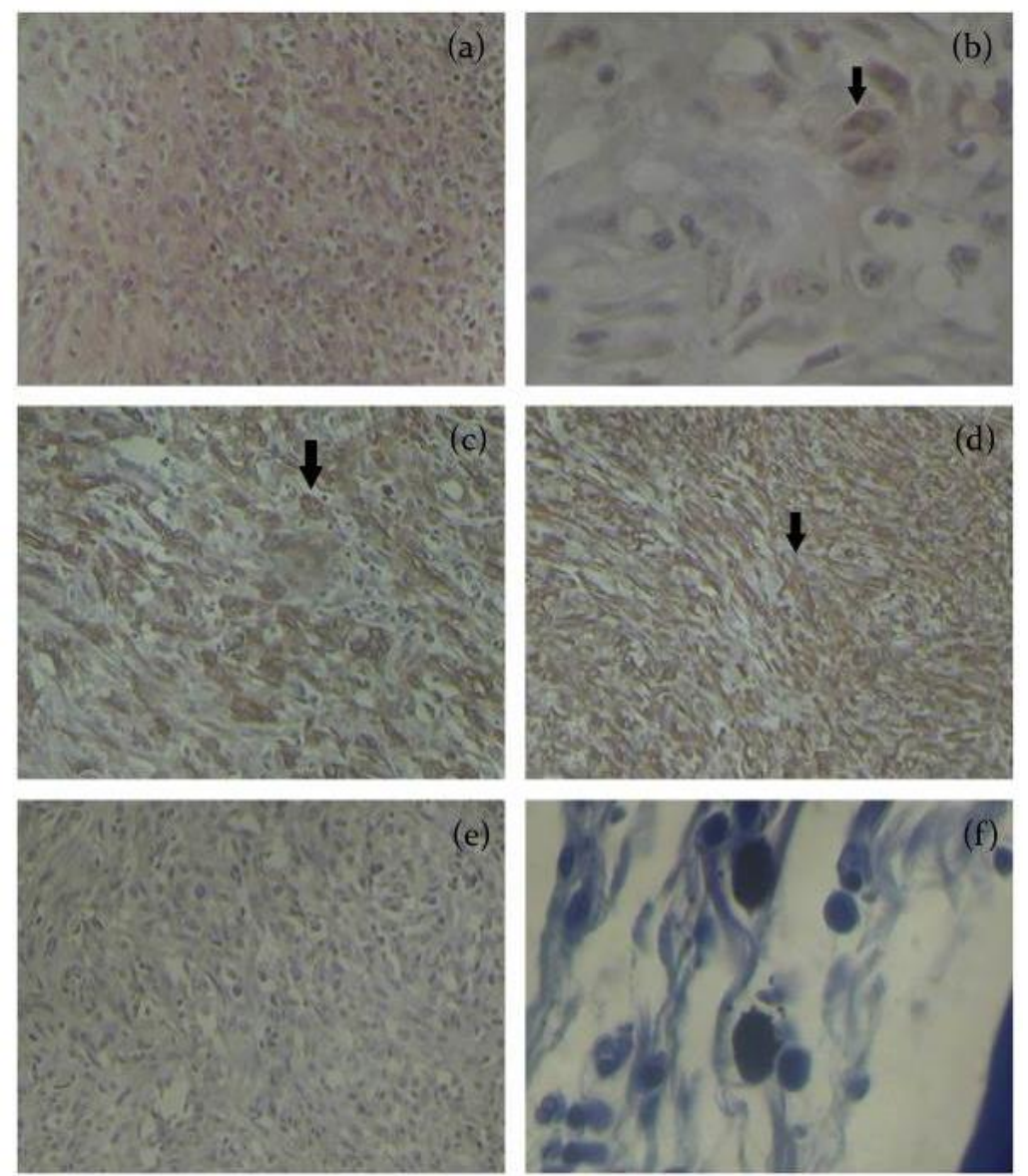

Fig. 4. Findings of immunohistochemistry (IHC) and Giemsa staining of LA7 induced tumors in rat. a: IHC-unstained, H\&E stained LA7 induced tumor tissue tumor. b: Ki67 positive cells, c: Cytokeratin positive cells, d: Vimentin positive cells (IHC), e: Estrogen receptor- negative cells (IHC), f: Mast cells (Giemsa stained) d: The magnification of a, c, d, e is $\times 400$ and b and $\mathrm{f}$ are $\times 1000$. 
Table 4. Data related to three proteins expected to be involved in stem cells differentiation and cells death induction, derived from an analysis of 16h-SFS solution by Mass spectrometry.

\begin{tabular}{|c|c|c|c|c|c|c|c|}
\hline & $\begin{array}{l}\text { Accession } \\
\text { Number } \\
\text { (uniport) }\end{array}$ & Protein & Taxonomy & Peptide Sequence & $\begin{array}{c}\text { Protein } \\
\text { Coverage }\end{array}$ & Rank & $\begin{array}{c}\text { Protein } \\
\text { score }\end{array}$ \\
\hline 1 & PEDF_HUMAN & $\begin{array}{l}\text { Pigment } \\
\text { epithelium } \\
\text { derived } \\
\text { factor }\end{array}$ & $\begin{array}{c}\text { Homo } \\
\text { sapiens }\end{array}$ & $\begin{array}{l}\text { KSLQEMKL } \\
\text { RVLTGNPRL } \\
\text { RTESIIHRA } \\
\text { KLTQVEHRA } \\
\text { KTVQAVLTVPKL } \\
\text { RDTDTGALLFIGKI } \\
\text { KLQSLFDSPDFSKI } \\
\text { KLAAAVSNFGYDLYRV } \\
\text { RKTSLEDFYLDEERT } \\
\text { RALYYDLISSPDIHGTYKELLDTVT } \\
\text { APQKN }\end{array}$ & $27.8 \%$ & $\begin{array}{l}1 \\
2 \\
1 \\
1 \\
1 \\
1 \\
1 \\
1 \\
1 \\
1\end{array}$ & 308 \\
\hline 2 & IBP7_HUMAN & $\begin{array}{l}\text { Insulin } \\
\text { like } \\
\text { growth } \\
\text { factor } \\
\text { binding } \\
\text { protein } 7\end{array}$ & $\begin{array}{c}\text { Homo } \\
\text { sapiens }\end{array}$ & $\begin{array}{l}\text { RGYCAPGMECVKS } \\
\text { RDACGCCPMCARG } \\
\text { KAGAAAGGPGVSGVCVCKS } \\
\text { RTELLPGDRDNLAIQTRG }\end{array}$ & $19.5 \%$ & $\begin{array}{l}1 \\
1 \\
1 \\
1\end{array}$ & 238 \\
\hline 3 & IBP5_HUMAN & $\begin{array}{l}\text { Insulin } \\
\text { like } \\
\text { growth } \\
\text { factor } \\
\text { binding } \\
\text { protein } 5\end{array}$ & $\begin{array}{c}\text { Homo } \\
\text { sapiens }\end{array}$ & RHMEASLQELKA & $3.7 \%$ & 1 & 34 \\
\hline
\end{tabular}

\section{Discussion}

In a previous in vitro study, we showed that the 16h-SFS solution was able to reduce the expression of stemness related genes in LA7 cells, a well-known rat mammary gland cancer stem cell line. This solution was also able to induce the necrotic pattern of cell death in these cells, and inhibited the cell migration in, in vitro assay for metastasis, i.e., scratch test (21). These findings led to the suggestion that the 16h-SFS solution has potentially beneficial effects in cancer stem cell differentiation. Thus, the main aim of this study was to examine the effects of 16h-SFS solution on the in vivo expression of stemness related genes in rat LA7 induced tumors. Interestingly, we observed that the expression of Oct4, Nanog and Sox 2 genes was downregulated in 16h-SFS treated tumors in comparison with tumors which were harvested from animals receiving normal saline and DMEM ( $\mathrm{p}<0.05)$. According to the $\mathrm{H} \& \mathrm{E}$ staining and IHC analysis performed here, it can be concluded that the tumor was established successfully in all LA7 received animals and differentiated into poorly sarcomatoid carcinoma with $\mathrm{Ki}^{+} 7^{+}$, cytokeratin ${ }^{+}$, vimentin ${ }^{+}$, and estrogen receptor negative phenotype. To the best of our knowledge, we are the first group to report such phenotype in LA7 cell induced tumor in rats. According to these data, the mitotic cells were observed in all groups. However, the prevalence of these cells was higher in normal saline treated tumors in comparison with the other groups ( $\mathrm{p}<0.05)$. Surprisingly, tumor focal necrosis was observed at higher frequency in 16h-SFS treated animals in comparison with the other groups. This observation was consistent with the other finding of the present study, namely reduction in tumor size in 16h-SFS treated animals, which was also confirmed by tumor radiography. It can be deduced from this finding that the observed elevated levels of tumor necrosis did 
not originate passively from ischemia, which usually occurs following obstruction of blood vessels located in the vicinity of growing tumor (31). To the best of our knowledge, there is no study reporting that the down-regulation of stemness genes directly triggers death in normal stem cells or CSCs. This in vitro and in vivo reduction in stemness related genes expression might appear as a secondary outcome, which was directly or indirectly triggered by an unknown stressor in 16h-SFS solution. In agreement with this hypothesis, $\mathrm{Hu}$ et al. showed that the oxidative stress was able to suppress NANOG and OCT4 expression through MAPK/ERK1/2 signaling pathway, and spontaneously differentiated these cells into neuronal cells in human embryonic stem cell model. There are several reports indicating that the redox state plays some pivotal roles in biology of mammalian stem cells, especially in hematopoietic stem cells (HSCs) (31-34). Contrary to mature tumor cells, CSCs are maintained in a niche with low levels of ROS. Elevated levels of ROS can kill stem cells (32). Interestingly, xenobiotic induced ROS can selectively kill cancer cells but not normal cells (31). We supposed that the 16h-SFS solution can also selectively kill CSCs but not normal cells. We have previously shown that $16 \mathrm{~h}-\mathrm{SFS}$ promoted the survival of our body ubiquitous cells, i.e., fibroblasts in serum free condition, and accelerated the post-refeeding proliferation in these cells (28). In the present study, the tumors derived from 16h-SFS treated animals exhibited relatively higher levels of angiogenesis, suggesting that $16 \mathrm{~h}-\mathrm{SFS}$ solution similar to xenobiotics might cause elevation in ROS concentrations in LA7 CSCs. Our mass spectrometry data supports this hypothesis. The IGFBP7 which was found in 16h-SFS might contribute to this process. IGFBP7 was classified as a secretory protein with tumor suppressor activity in hepatocellular carcinoma which induced the generation of reactive oxygen species and the induction of response to DNA damage in those cells (30). However, another study at mRNA expression level is required to confirm this hypothesis. Moreover, the over expression of IGFBP5 decreased the expression of the key stem cell markers NANOG, SOX2, OCT4, KLF4, and CD133 (35). 16h-SFS solution also comprised this type of protein. Another protein with an important role in tumor biology is PEDF, which has been already identified as anti-tumor protein. PEDF ablation resulted in increased levels of the cancerous cell proliferation, invasion and metastasis (36). In addition, PEDF was able to induce peroxisome-proliferator receptor gamma (PPAR- $\gamma)$ gene expression in endothelial cells (36), which has been reported to elevate the ROS levels and inhibit tumorigenesis (37).

We found mast cells in tumors of DMEM and 16h-SFS receiving animals. The mast cells play pivotal roles in tumor angiogenesis and neovascularization by secreting proangiogenic factors such as vascular endothelial growth factor (VEGF), interleukin-6 (IL-6), platelet derived growth factor (PDGF), and fibroblast growth factor-2 (FGF2) (38). We observed that other leucocytes were also considerably infiltrated in the induced tumors, albeit with different cellular patterns, implicating the immunogenic capacity of the LA7 induced tumors. While the PMNCS were the predominant migratory cells in normal saline treated tumors, the 16h-SFS and DMEM treated tumors exhibited a mixed pattern of inflammatory cell migration. Further studies are required to provide detailed immunophenotyping of these cells to interpret this discrepancy and to understand its contribution to defense against induced tumors.

Taken together, the data generated by this study showed that the substances released from human fibroblasts under serum starvation stress are able to down-regulate the stemness-related genes and induce necrosis in LA7 CSCs derived tumors. Moreover, this study introduced a model for a better understanding of the cross talk between CSCs and tumor stromal cells.

\section{Acknowledgements}

This study was financially supported by the Cellular and Molecular Biology Research Center of Babol University of Medical Sciences.

The authors declare that there is no conflict of interest. 


\section{References}

1. Ma Y, Machesky LM. Fascin1 in carcinomas: Its regulation and prognostic value. International Journal of Cancer. 2014;137(11):2534-2544.

2. Sadlonova A, Novak Z, Johnson M R, Bowe DB. Breast fibroblasts modulate epithelial cell proliferation in three-dimensional in vitro co-culture. Breast Cancer Research. 2005;7(1):R46-59.

3. Su S, Chen J, Yao H, Liu J, Yu S, Lao L, et al. CD10(+)GPR77(+)

Cancer-Associated

Fibroblasts Promote Cancer Formation and Chemoresistance by Sustaining Cancer Stemness. Cell. 2018;172(4):841-56.e16.

4. Munoz P, Iliou M S, Esteller M. Epigenetic alterations involved in cancer stem cell reprogramming. Mol Oncol. 2012;6(6):620-36.

5. Yamanaka S. Induction of pluripotent stem cells from mouse fibroblasts by four transcription factors. Cell. 2008;126(4):663-76.

6. Van Schaijik B, Davis P F, Wickremesekera A C, Tan ST, Itinteang T, et al. Subcellular localisation of the stem cell markers OCT4, SOX2, NANOG, KLF4 and $c-M Y C$ in cancer: a review. J Clin Pathol. 2018;71(1):88-91.

7. Esch D, Vahokoski J, Groves M R, Pogenberg $\mathrm{V}$, Cojocaru V, Vom Bruch $\mathrm{H}$, et al. A unique Oct4 interface is crucial for reprogramming to pluripotency. Nat Cell Biol. 2013;15(3):295-301. 8. Munro M J, Wickremesekera S K, Peng L, Tan ST, Itinteang T. Cancer stem cells in colorectal cancer: a review. J Clin Pathol. 2018;71(2):110-116.

9. Sarkar A, Hochedlinger K. The sox family of transcription factors: versatile regulators of stem and progenitor cell fate. Cell Stem Cell. 2013;12(1):15-30.

10. Ghazi N, Aali N, Shahrokhi V R, Mohajertehran F, Saghravanian N. Relative Expression of SOX2 and OCT4 in Oral Squamous Cell Carcinoma and Oral Epithelial Dysplasia. Rep Biochem Mol Biol. 2020;9(2):171-179.

11. Jeter C R, Yang T, Wang J, Chao HP, Tang DG. Concise Review: NANOG in Cancer Stem Cells and Tumor Development: An Update and Outstanding Questions. Stem Cells. 2015;33(8):2381-90.
12. You L, Guo X, Huang Y. Correlation of Cancer Stem-Cell Markers OCT4, SOX2, and $N A N O G$ with Clinicopathological Features and Prognosis in Operative Patients with Rectal Cancer. Yonsei Med J. 2018;59(1):35-42.

13. Xiang R, Liao D, Cheng T, H Zhou, Q Shi, T $S$ Chuang, et al. Downregulation of transcription factor SOX2 in cancer stem cells suppresses growth and metastasis of lung cancer. $\mathrm{Br} \mathbf{J}$ Cancer. 2011;104(9):1410-7.

14. Leis O, Eguiara A, Lopez-Arribillaga E, et al. Sox2 expression in breast tumours and activation in breast cancer stem cells. Oncogene. 2012;31(11):1354-65.

15. Sousa B, Ribeiro A S, Paredes J. Heterogeneity and Plasticity of Breast Cancer Stem Cells. Adv Exp Med Biol. 2019;1139:83-103.

16. Garg M. Epithelial plasticity and cancer stem cells: Major mechanisms of cancer pathogenesis and therapy resistance. World J Stem Cells. 2017;9(8):118-126.

17. Britain C M, Dorsett K A, Bellis S L. The Glycosyltransferase ST6Gal-I Protects Tumor Cells against Serum Growth Factor Withdrawal by Enhancing Survival Signaling and Proliferative Potential. J Biol Chem. 2017;292(11):4663-4673.

18. Tian X, Huang B, Zhang X P, Lu M, Liu F, Onuchic JN, et al. Modeling the response of a tumorsuppressive network to mitogenic and oncogenic signals. PNAS. 2017;114(21):5337-5342.

19. Sun H, Chen L, Cao S, Liang Y, Xu Y, et al. Warburg Effects in Cancer and Normal Proliferating Cells: Two Tales of the Same Name. Genomics Proteomics Bioinformatics. 2019;17(3):273-286.

20. Golpour M, Akhavan Niaki H, Khorasani H R, Hajian A, Mehrasa R, A Mostafazadeh, et al. Human fibroblast switches to anaerobic metabolic pathway in response to serum starvation: a mimic of warburg effect. Int $\mathbf{J}$ Mol Cell Med. 2014;3:74-80.

21. Pourbagher R, Akhavan Niaki H, Ali Jorsaraei S G A. Targeting breast cancer stem cells of rat through repressing the genes of stemness-related transcription factors using three different biological fluids. Gene. 2020; 15;734:144381. 
22. Zucchi I, Sanzone S, Astigiano S, Pelucchi P, Scotti M, Valsecchi V, et al. The properties of a mammary gland cancer stem cell. Proc Natl Acad Sci U S A. 2007;104(25):10476-81.

23. Oyenihi O R, Krygsman A, Verhoog N, Beer D, Saayman MJ, Mouton TM, et al. Chemoprevention of LA7-Induced Mammary Tumor Growth by SM6Met, a WellCharacterized Cyclopia Extract. Front Pharmacol. 2018;9:650.

24. Brook N, Brook E, Dharmarajan A, Chan A, Dass CR, et al. The role of pigment epitheliumderived factor in protecting against cellular stress. Free Radic Res. 2019;53(11-12):1166-1180.

25. Akkiprik M, Feng Y, Wang H, Hu L, Sahin

A, Krishnamurthy S, et al. Multifunctional roles of insulin-like growth factor binding protein 5 in breast cancer. Breast Cancer Res.

2008;10(4):212.

26. Chen D, Siddiq A, Emdad L, Rajasekaran D, Gredler R, Shenet XN, et al. Insulin-like growth factor-binding protein-7 (IGFBP7): a promising gene therapeutic for hepatocellular carcinoma (HCC). Mol Ther. 2013;21(4):758-66.

27. Pandamooz S, Hadipour A, Akhavan-Niaki H, Pourghasem M, Abedian Z, Motevallizadeh Ardekani A, et al. Short exposure to collagenase and coculture with mouse embryonic pancreas improve human dermal fibroblast culture. Biotechnol Appl Biochem. 2012;59(3):254-61.

28. Golpour M, Fattahi S, Niaki H A, Hadipoor A, Abedian Z, Ahangarianet GR, et al. Starved human fibroblasts secrete acidic proteins inducing post re-feeding proliferation and in vitro cell migration: a potential tool for wound healing. Biol Cell. 2014;106(5):139-50.

29. Fattahi S, Amirbozorgi G, Lotfi M, Amini Navaei B, Kavoosian S, Asouri M, et al. Development of a Universal Taqman Probe for mRNA Gene Expression Analysis. Iranian Journal of Science and Technology, Transaction A: Science. 2018;42:363-370.
30. Wang M, Chen C, Jemielita T, Anderson J, Nicole $\mathrm{X}, \mathrm{Hu} \mathrm{C}$, et al. Are tumor size changes predictive of survival for checkpoint blockade based immunotherapy in metastatic melanoma? J Immunother Cancer. 2019;7(1):39.

31. Shi X, Zhang Y, Zheng J, et al. Reactive oxygen species in cancer stem cells. Antioxid Redox Signal. 2012;16:1215-28.

32. Hu Q, Khanna P, Ee Wong B S, Heng ZSL, CS Subhramanyam, LZ Thanga, et al. Oxidative stress promotes exit from the stem cell state and spontaneous neuronal differentiation. Oncotarget. 2018;9:4223-38.

33. Papa L, Djedaini M, Hoffman R. Mitochondrial Role in Stemness and Differentiation of Hematopoietic Stem Cells. Stem Cells International. 2019;2019.

34. Liang $R$ and Ghaffari S. Stem cells, redox signaling, and stem cell aging. Antioxid Redox Signal. 2014;20:1902-16.

35. Wang J, Ding N, Li Y, Cheng H, Wang D, Yang Q, et al. Insulin-like growth factor binding protein 5 (IGFBP5) functions as a tumor suppressor in human melanoma cells. Oncotarget. 2015;6(24):20636-20649.

36. Belkacemi L, Zhang S X. Anti-tumor effects of pigment epithelium-derived factor (PEDF): implication for cancer therapy. A mini-review. J Exp Clin Cancer Res. 2016;35:4.

37. Srivastava N, Kollipara R K, Singh D K, Sudderth J, Hu Z, Nguyen H, et al. Inhibition of cancer cell proliferation by PPARgamma is mediated by a metabolic switch that increases reactive oxygen species levels. Cell Metab. 2014;20(4):650-61.

38. Komi DEA,Redegeld FA. Role of Mast Cells in Shaping the Tumor Microenvironment. linical Reviews in Allergy \& Immunology.

2020;58:313-325. 